\title{
Are Training Programs Efficient Enough to Improve Spirometry Quality in Primary Care?
}

Pilar Carmen Cebollero*, Maria Carmen Bermejo, Jose Antonio Cascante, Francisco Campano, Jorge Zagaceta, Izaskun Jiménez and Javier Hueto

Pneumology Service of Complejo Hospitalario de Navarra, Spain

\begin{abstract}
Objective: To analyse the spirometry situation in primary care (PC), in terms of its use as well as its quality, one decade after our first analysis and to evaluate the effectiveness of the plans instituted since then.

Methodology: In the first phase, a survey of all health centres (centros de salud, CSs, in Spanish), similar to the one used in 2005, was conducted in which information was requested regarding spirometric equipment, frequency of use, calibration, and personnel training. Subsequently, 96 patients were referred from PC after having a baseline spirometry conducted at a CS. The spirometry was repeated the same morning with a similar spirometer in the pneumology laboratory. Two expert pneumologists in functionalism analysed the quality of the tests according to the ATS/ERS and SEPAR regulations and compared the results with these obtained in 2005.
\end{abstract}

Results: A spirometer is available in $100 \%$ of the CSs (90.9\% in 2005). Spirometries are performed in $91.8 \%$, and in $80.3 \%$, daily calibration is performed (4\% in 2005). However, the number of spirometries remains similar to that found in our previous study and lower than desired. With respect to their quality, only $40.5 \%$ of the 96 tests analysed had sufficient quality (A, B or C in a scale from A to $F$ ). The spirometric diagnosis was wrong in $43.7 \%$ of the cases (39.7\% in 2005), corresponding to an absence of agreement in $29.1 \%$ and a discrepancy in the severity in $13.5 \%$.

Conclusions: Spirometry in PC continues to be an unresolved problem in our area, and we have ascertained that exclusively training and non-continuing programmes yield insufficient results. Given the magnitude of the problem and knowledge of the existence of projects that have demonstrated their effectiveness, we believe there should be no further delay in implementing any of these strategies adapted to each area.

Keywords: Spirometry; Primary care; Quality; Training; Telespirometry; Education

\section{Introduction}

Among the respiratory diseases are some of the most prevalent chronic conditions, such as asthma or COPD [1,2], with spirometry being the essential tool for their diagnosis and monitoring. This exploration is also essential in other circumstances, such as the evaluation of incapacity for work or interstitial pathology. The COPD Strategy of the National Health System in Spain states that it "is essential to diagnose the disease and to assess its severity and that, in addition, to establish its prognosis, to guide the treatment, to facilitate the control of the therapeutic response and the progression of the disease"[3]. The European Respiratory Society (ERS) is committed to improving the use and quality of spirometry and currently, among other actions, is developing the European Spirometry Training Programme to help health professionals achieve quality spirometry and obtain the accreditation certificate. On the other hand the General Practice Airways Group (GPIAG) in association with the Association for Respiratory Technology and Physiology (ARTP) and Education for Health several years before had already published their Proposed Standards for general practice compliant with American Thoracic Society and European Respiratory Society [4].

The under diagnosis and incorrect diagnosis of respiratory diseases are established facts [5-7]. Regarding the former, in COPD, some studies place under diagnosis at more than $70 \%[5,8]$. Moreover, a study conducted in Australia found that $31 \%$ of the patients diagnosed with COPD had not undergone spirometry [9].

Our group analysed the spirometry situation in primary care (PC) in Navarre (Spain) in 2005, ascertaining that, at that time, the majority of the health centres (centros de salud, CSs, in Spanish) provided spirometers and in turn observing a marked underutilization of the devices, poor monitoring of the recommendations for implementing PC spirometry, and inadequate quality of the spirometry performed in that care setting [10]. In recent years, several studies have examined the spirometry situation [11-14], having evaluated and implemented initiatives of various types [15-20]. During this period in our community, measures aimed at training PC health personnel and improving CS equipment was adopted. Therefore, we were interested in re-evaluating the situation, both in terms of utilization as well as in quality, 10 years after our first analysis.

\section{Methodology}

In essence, the systematic methodology used was similar to that employed in our 2005 study and was conducted in two phases. The first phase was learning about the current spirometry situation in PC in our community in terms of knowledge, resources, and use. As in our previous work, a simultaneous survey of all CSs (an assisted population of 640,000 inhabitants) was performed. In the second phase, prospectively, the quality of spirometries performed at that level of care was analysed.

*Corresponding author: Pilar Carmen Cebollero, Pneumology Service of Complejo Hospitalario de Navarra, Spain, Tel: +34 8484222 22; E-mail: pilar473@me.com

Received August 18, 2016; Accepted September 24, 2016; Published September 27, 2016

Citation: Cebollero PC, Bermejo MC, Cascante JA, Campano F, Zagaceta J, et al. (2016) Are Training Programs Efficient Enough to Improve Spirometry Quality in Primary Care? J Pulm Respir Med 6: 368. doi: 10.4172/2161-105X.1000368

Copyright: ( 2016 Cebollero PC, et al. This is an open-access article distributed under the terms of the Creative Commons Attribution License, which permits unrestricted use, distribution, and reproduction in any medium, provided the original author and source are credited. 


\section{Development of the study and selection criteria of the sample}

The survey was distributed to all CSs under the direction of PC, and the data were recorded through a questionnaire that included virtually the same variables as in the previous study (Figure 1).

Once the results thereof were known and analysed, the CSs that performed spirometries were again divided into two groups, depending on the number of tests performed per week (group I: five or more spirometries, group II: less than five spirometries). The homogeneity of the population cared for and the proximity to the pulmonary function laboratory of specialized care (SC) were considered in the implementation of the second phase of the study. Finally, 10 CSs (four in group I and six in group II), attending to a population of 144,985 inhabitants $(22.6 \%$ of the total) were selected.

Between February and June 2015, the PC teams of the assigned CSs were instructed to systematically refer patients according to the inclusion criteria explained in Figure 2. As an improvement over the previous methodology, patients underwent spirometry the same morning at the two levels of care, and the spirometer used in both events was a Datospir 120 (Sibelmed, Barcelona-Spain). The nurses of the pulmonology laboratory completed a second questionnaire with the patient, in which it was ensured that the patient met the inclusion criteria, anthropometric data were obtained, and the educational level,

1.- Way of spirometry performance:

Centralized (always the same nurse/nurse team)

Non centralized (nonspecific nurse to do it)

No spirometries performance in that centre

Others:

Responsible nurse: yes/no

Alternate nurse: yes/no

2.- Spirometer model:

Datospir 100

Datospir 120

Datospir 120 c

Others:

3.- Do you know the reference values used by your spirometer? Yes/No

4.- Number of spirometries performed per week:

None

$<5$

$5-10$

$10-20$

$>20$

5.- Thermometer and barometer available? Yes/No

6.- Calibration syringe available? Yes/No

7.-Do you calibrate following recommendations? Yes/No

8.-Do you calibrate every spirometry session? Yes/No

9.- Do you register your calibrations? Yes/No

10.-Do you give your patients systematic instructions before the test? Yes/No

11.- Have you received supervised training in spirometry? Yes/No

12.-Last training course received:

$<3$ months

3-6 months

6 months-1 year

$>1$ year

Figure 1: Survey on spirometry conducted in 2015 with all PC teams of Navarre. smoking status, and reason for seeking care were collected. The nurses then proceeded to perform the test, strictly following the quality criteria of the ATS/ERS [21] and SEPAR regulations [22]. The patient brought in a sealed envelope, containing the spirometry performed in the CS with all attempts printed so that the SC nurse was unaware of the quality/ result of the PC test. Subsequently, all spirometries performed in PC and $\mathrm{SC}$ was anonymized for further analysis by two pulmonologists of the functional exploration laboratory. In addition to the acceptability of the spirometries analysed in 2005 , on this occasion, the analysis was completed with the study and validation of repeatability, finally classifying the quality into levels A-F, as stated in the regulations [22], taking levels $\mathrm{A}, \mathrm{B}$, and $\mathrm{C}$ as reasonably acceptable.

\section{Statistical analysis}

Sample size calculation: Assuming an expected proportion of PC spirometries of acceptable quality (A, B, or C) of $40 \%$, the sample size necessary to achieve an estimation accuracy $\pm 10 \%$ was at least 91 individuals. This sample size guaranteed a statistical power of $80 \%$ for detecting significant differences in the proportion of acceptable qualities between PC and SC of at least $22 \%$, with a confidence level of 95\% (calculations were performed using the epiR and clinfun libraries of the R statistical package).

The degree of adjustment to the normality of the sample was ascertained by means of the Kolmogorov-Smirnov test. For the descriptive study, the quantitative data are expressed as means $\pm \mathrm{SD}$, the qualitative data as percentages, and their differences through the Wilcoxon test and Student's t-test for related samples. A nonparametric analysis of variance was performed using the Kruskal-Wallis contrast test to verify the equality between distributions; the morphologies of the curves were studied using a contrast of two proportions. The $\chi^{2}$ test was used for the comparative analysis of the total quality. A p-value of 0.05 was considered to be the limit of significance in all analyses.

\section{Results}

All of the CSs (61) completed the survey sent, and the results obtained are shown, compared with those of 2005, in Table 1. Currently, all PC teams provide a spirometer, a slight improvement compared with the previously evaluated situation, and the models used have been updated and homogenized. We also found a significant improvement in terms of the provision of necessary equipment, knowledge of the reference values, and daily calibration and record keeping. A significant improvement in the number of CSs that perform spirometries was also observed, although no changes were seen in the number of spirometries performed per week in the different CSs, which continues to be less than desired. Likewise, there have been no changes during these 10 years in the degree of training of the personnel performing the tests.

In the second phase of the study, with the objective of analysing the quality of the spirometries, 110 patients underwent spirometry in PC and SC, excluding 14 (12.7\%) who did not meet the inclusion criteria, with the final sample being 96 patients. Table 2 reflects the characteristics of the study population, highlighting, as a difference with respect to our previous study, a higher level of studies and similarity in weight and size between the two levels of care (average weight: PC 73 and SC 72.9; average size: PC 164 and SC 163.2).

In relation to the determination of $\mathrm{FVC}$ and $\mathrm{FEV}_{1}$, the correlation between PC and SC remains high ( $r=0.93$ and $r=0.95$, respectively). Table 3 shows the results of the acceptability of the curves and their comparison with those of 2005, demonstrating the absence of improvement in PC during this time. Analysing the overall acceptability (start, slope, and end) of 2015 between PC and SC, a significant difference $(\mathrm{p}<0.001)$ 
Citation: Cebollero PC, Bermejo MC, Cascante JA, Campano F, Zagaceta J, et al. (2016) Are Training Programs Efficient Enough to Improve Spirometry Quality in Primary Care? J Pulm Respir Med 6: 368. doi:10.4172/2161-105X.1000368

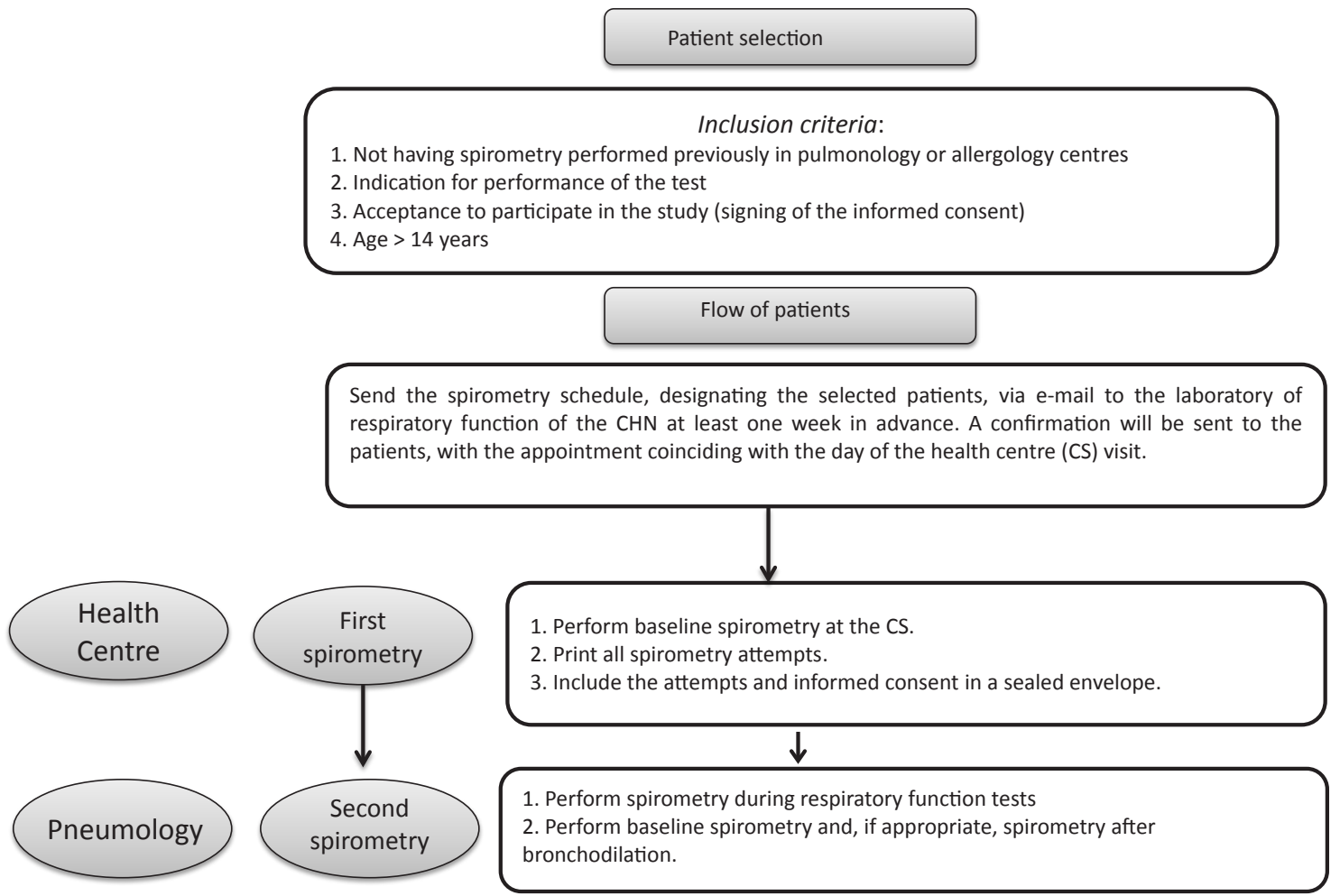

Figure 2: Inclusion criteria and patient referral flow.

\begin{tabular}{|c|c|c|c|}
\hline \multirow{2}{*}{ Variables } & 2005 & 2015 & \multirow{2}{*}{$\mathbf{p}$} \\
\hline & $\mathrm{N}^{\circ}(\%)$ & $\mathrm{N}^{\circ}(\%)$ & \\
\hline Number of centres & 55 & 61 & \\
\hline Spirometry availability & $50(90.9)$ & $61(100)$ & NS \\
\hline \multicolumn{4}{|l|}{ Model of spirometer (n 2005=50; n 2015=61) } \\
\hline Datospir 100 & $36(72)$ & $15(24.5)$ & \\
\hline Datospir 120 & $4(8)$ & $46(75.4)$ & \\
\hline Others & $10(20$ & 0 & \\
\hline Thermometer/barometer (n 2005=50; n 2015=61) & $4(8)$ & $54(88.5)$ & $<0.0001$ \\
\hline Syringe availability (n 2005=50; n 2015=61) & $7(14)$ & $49(80.3)$ & $<0.0001$ \\
\hline Daily calibration (n 2005=50; n 2015=61) & $2(4)$ & $49(80.3)$ & $<0.0001$ \\
\hline Calibration register (n 2005=50; n 2015=61) & 0 & $40(65.5)$ & $<0.0001$ \\
\hline Reference values knowledge (n 2005=50; n 2015=61) & $2(4)$ & $40(65.5)$ & $<0.001$ \\
\hline Spirometry performance (number of centres and \%) & $34(61.8)$ & $56(91.8)$ & $<0.001$ \\
\hline Number of spirometries/week ( $2005=50 ; n$ 2015=61) & & & NS \\
\hline 0 & $11(22)$ & $5(8,1)$ & \\
\hline $0-5$ & $31(62)$ & $43(70.4)$ & \\
\hline $06-10$ & $6(12)$ & $12(19.6)$ & \\
\hline $11-20$ & $2(4)$ & $1(1.6)$ & \\
\hline$>20$ & 0 & 0 & \\
\hline Previous training course on spirometry & $25(64)^{*}$ & $41(59.4)^{*}$ & NS \\
\hline
\end{tabular}

*number of nurses interviewed (39 in 2005 y 69 in 2015)

Table 1: Results obtained in the 2005 and 2015 surveys.

was evident in favour of the latter (Table 4). The percentages of quality obtained in PC were $21.8 \%$ of the tests having a quality of $\mathrm{A}$ or B and $18.7 \%$ a quality of C (acceptable quality $40.5 \%$ ) and in SC $72.9 \%$ and $11.4 \%$, respectively (acceptable quality $92.7 \%$ ), $\mathrm{p}<0.0001$. Table 5 shows the acceptability and the quality of the spirometries analysed in relation to the number of tests conducted in the CSs, classified into two groups (more or less than five spirometries/week), with significant differences existing in both. Table 6 shows the correlation of the functional diagnosis between PC and the pulmonology laboratory in the two studies. The percentage of diagnostic errors is now slightly higher than that found previously ( $43.7 \%$ vs. $39.7 \%$ in 2005). Currently $13.5 \%$ of the diagnostic errors correspond to a misclassification of the severity and $29.1 \%$ to an absence of diagnostic agreement (diagnostic differences PC-SC/2015: $\mathrm{p}=0.0001)$. 


\begin{tabular}{|c|c|c|c|}
\hline Variables & $\mathbf{2 0 0 5}$ & $\mathbf{2 0 1 5}$ & $\mathbf{p}$ \\
\hline Number of patients (\%) & $171(100)$ & $96(100)$ & \\
\hline Mean age \pm SD & $51.75 \pm 16.8$ & $58.1 \pm 15$ & NS \\
\hline Gender (\%) & & & NS \\
\hline Males & 50.8 & 42.7 & \\
\hline Females & 49.1 & 57.3 & \\
\hline Level of studies (\%) & $163(100)$ & $96(100)$ & $<0.01$ \\
\hline Uneducated & 7.9 & 3.1 & \\
\hline Primary studies & 55.2 & 39.5 & \\
\hline Secondary studies & 23.9 & 35.4 & \\
\hline Graduate & 12.8 & 21.8 & \\
\hline Smoking status (\%) & $166(100)$ & $96(100)$ & NS \\
\hline Never smoker & 30.7 & 26 & \\
\hline Smoker >40 accumulated packages-year & 24 & 30.2 & \\
\hline Smoker <40 accumulated packages-year & 15.6 & 19.7 & \\
\hline Ex-smoker >6 months >40 accumulated & 14.4 & 13.5 & \\
\hline packages-year & 15 & 10.4 & \\
\hline Ex-smoker $>6$ months <40 accumulated & & & \\
\hline packages-year & $168(100)$ & $96(100)$ & 0.05 \\
\hline Reason for submission (\%) & 7.7 & 8.3 & \\
\hline COPD suspicion & 7.7 & 1 & \\
\hline Asthma suspicion & 25 & 18.7 & \\
\hline Dyspnoea & 59.5 & 71.8 & \\
\hline Others & & \\
\hline
\end{tabular}

SD: Standard Deviation; COPD: Chronic Obstructive Pulmonary Disease; NS: No Significative

Table 2: Characteristics of the populations studied in 2005 and 2015

\section{Discussion}

Although for several years, the correct use of spirometry in PC has been considered a priority objective in many health plans, it continues to be an unresolved problem. In Navarre, in 2005, we detected a marked underutilization and improvable quality of the tests, yet there were an adequate number of spirometers in the CSs. The current situation reflects an increase in the CSs that perform spirometries, as well as an improvement in their supply, calibration, records of particular variables, and knowledge of reference values. These data are similar in some respects to those detected in a recent national study [14]. However, we found no significant changes from our previous analysis of the number of explorations per week, which remains low and coincident with that referenced in the $3 \mathrm{E}$ study [13].

Of special interest is the analysis of the quality of the curves, and their evolution during this time can be deduced from our findings. Following the methodology employed in our first study, in which only the acceptability was taken into account, it has been noted that no significant changes have been produced in spirometries performed in PC in terms of their start, slope, and end. At present, the number of curves satisfactorily complying with the three criteria is similar to that shown by the control group in the study of Burgos et al. [16] and less than that found in our SC laboratory and that recommended by other authors [23] but slightly improved in those CSs in which a greater number of spirometries is performed, although this number continues to be insufficient. Applying the classification of quality recommended by the consensus of both the ERS/ATS and SEPAR [21,22], only $40.5 \%$ attain sufficient quality in PC. Again, in this section, the result improves depending on the number of spirometries performed. The difference observed between the percentages of acceptability and of sufficient quality $(A, B, C)$ could be explained by the fact that, of the 33 cases that were classified as level E, 19 (57.5\%) had only one curve for evaluation. The impact derived from these results in terms of diagnostic errors

\begin{tabular}{|c|c|c|c|c|c|c|}
\hline \multirow{2}{*}{ Variables } & \multicolumn{2}{|c|}{ Primary Care } & \multirow{2}{*}{$\mathbf{P}$} & \multicolumn{2}{|c|}{ Pneumology Service } & \multirow{2}{*}{ P } \\
\cline { 2 - 5 } \cline { 5 - 6 } & $\mathbf{2 0 0 5}$ & $\mathbf{2 0 1 5}$ & & $\mathbf{2 0 0 5}$ & $\mathbf{2 0 1 5}$ & \\
\hline Good start & 76.6 & 83.3 & NS & 91.2 & 98.9 & $<0.05$ \\
\hline Good slope & 77.8 & 77 & NS & 88.3 & 93.7 & NS \\
\hline Good end & 84.8 & 84.3 & NS & 95.9 & 95.8 & NS \\
\hline
\end{tabular}

Table 3: Results for the acceptability of the curves in 2005 and 2015.

\begin{tabular}{|c|c|c|c|}
\hline Acceptability n ${ }^{\circ}$ curves (\%) & Primary Care & Pneumology Service & p \\
\hline Good start & $80(83.3)$ & $95(98.9)$ & $<0.001$ \\
\hline Good slope & $74(77)$ & $90(93.7)$ & $<0.001$ \\
\hline Good end & $81(84.3)$ & $92(95.8)$ & $<0.001$ \\
\hline $\begin{array}{c}\text { Good curve } \\
\text { (start+slope+end) }\end{array}$ & $61(63.5)$ & $85(88.5)$ & $<0.001$ \\
\hline
\end{tabular}

Table 4: Acceptability of the PC and Pneumology Service curves in 2015.

\begin{tabular}{|c|c|c|c|}
\hline & Group $^{*}$ ( $\mathbf{n = 5 8 )}$ & Group 2** $^{* \mathbf{n}=\mathbf{3 8})}$ & $\mathbf{p}$ \\
\hline A, B o C (\%) quality & 28 & 11 & 0.05 \\
\hline Acceptability & 43 & 18 & 0.007 \\
\hline
\end{tabular}

*Frequency >5 spirometries/week; ** $\leq 5$ spirometries/week; ERS 2005/SEPAR 2013 criteria

Table 5: Comparison of the PC spirometry quality according to the number of tests conducted in the CSs (2015).

has not improved, although the trend of the false classification of nonobstructive patterns has diminished in favour of other errors or the intensity of the severity.

During these years, the actions taken under the direction of PC planners have focused on improving the supply of CSs, which, as noted, have served their purpose, and the theoretical and practical training of health personnel. During the years 2005-2008, workshops were conducted for the responsible and alternate physicians and nurses in all CSs. In 2009, the management itself evaluated certain aspects consequential to the improvement programme. Using a survey, they ascertained that $65 \%$ of the responsible nurses and $45 \%$ of the alternates had received the training programme. The management considered the centralization of the test in a responsible nurse or his/her alternate, daily calibration, and recording keeping as the main criteria of quality. The results obtained showed the existence of lines of improvement (PC internal document, unpublished data). The quality of the tests was not evaluated. Undoubtedly, all efforts to improve the training of the staff involved are laudable, but in our area, it does not seem to have yielded a final improvement of the level of training, as the percentage of people trained continued to be stable. An explanation of this fact, as we noted in our first study, may be related to the system of recruitment and the possibility of mobility in the workplace of the nursing personnel, making it difficult to get properly trained technicians who have continuity in the workplace [10]. As early as 1999, Eaton et al. [24] ascertained that a timely intervention with a spirometry-training workshop did not guarantee the quality of the procedure. Recently, several authors have evaluated the effectiveness, in the short and long term, of tutored spirometry training for PC professionals, ascertaining the need for periodic training and a smooth coordination between PC and SC to maintain an adequate level of education $[17,19,23]$.

Moreover, various task forces have been implementing, through the development of new technologies, telemonitoring systems that have been shown to improve the quality of spirometry and the appropriateness of its use in PC. Some of them are noted for facilitating, in addition to training, continuous feedback between professionals, which favours the maintenance of the quality achieved $[15,16,18,25-27]$. 


\begin{tabular}{|c|c|c|c|c|c|c|c|c|c|c|c|c|c|c|c|c|c|c|c|c|c|c|c|c|c|c|c|c|c|c|}
\hline \multirow{3}{*}{$\begin{array}{c}\text { Pneumology Service diagnosis } \\
\qquad \mathrm{N} \text { (Normal) }\end{array}$} & \multicolumn{2}{|c|}{ Total } & \multicolumn{28}{|c|}{ Primary Care Diagnosis } \\
\hline & \multirow{2}{*}{\begin{tabular}{|c|}
2005 \\
69 \\
\end{tabular}} & \multirow{2}{*}{\begin{tabular}{|c|}
2015 \\
42
\end{tabular}} & \multicolumn{2}{|c|}{$\mathbf{N}$} & \multicolumn{2}{|c|}{ MiO } & \multicolumn{2}{|c|}{ MO } & \multicolumn{2}{|c|}{ MSO } & \multicolumn{2}{|c|}{ so } & \multicolumn{2}{|c|}{ MiNO } & \multicolumn{2}{|c|}{ MNO } & \multicolumn{2}{|c|}{ MSNO } & \multicolumn{2}{|c|}{ SNO } & \multicolumn{2}{|c|}{ M } & \multicolumn{2}{|c|}{ MIM } & \multicolumn{2}{|c|}{ MM } & \multicolumn{2}{|c|}{ MSM } & \multicolumn{2}{|c|}{ SM } \\
\hline & & & 54 & 34 & 5 & 5 & & & & & & & 10 & 1 & & & & 1 & & & & & & 1 & & & & & & \\
\hline $\mathrm{MiO}$ (Mild obstruction) & 71 & 24 & 20 & 8 & 26 & 13 & 6 & 3 & & & 1 & & 16 & & & & & & & & 2 & & & & & & & & & \\
\hline MO (Moderate obstruction) & 17 & 7 & & 1 & 2 & 1 & 11 & 1 & & 1 & 1 & & 2 & 1 & & & & & & & 1 & & & 1 & & 1 & & & & \\
\hline MSO (Moderately severe obstruction) & & 1 & & & & & & & & & & & & & & 1 & & & & & & & & & & & & & & \\
\hline SO (Severe obstruction) & 2 & 4 & & & & & 1 & & & 1 & 1 & 2 & & & & & & & & & & & & & & & & 1 & & \\
\hline MiNO (Mild non obstructive pattern) & 12 & 6 & 1 & & & & & & & & & & 11 & 2 & & 1 & & 1 & & 1 & & & & & & & & 1 & & \\
\hline MNO (Moderate non obstructive pattern) & & 1 & & & & & & & & & & & & & & 1 & & & & & & & & & & & & & & \\
\hline MSNO (Moderately severe non obstructive pattern) & & 1 & & & & & & & & & & & & & & 1 & & & & & & & & & & & & & & \\
\hline \multicolumn{31}{|l|}{ SNO (Severe non obstructive pattern) } \\
\hline \multicolumn{31}{|l|}{ M (Mixed pattern) } \\
\hline MiM (Mild mixed pattern) & & 3 & & 1 & & 1 & & & & & & & & & & & & 1 & & & & & & & & & & & & \\
\hline \multicolumn{31}{|l|}{ MM (Moderate mixed pattern) } \\
\hline MSM (Moderately Severe mixed pattern) & & 4 & & & & & & 1 & & & & & & & & 1 & & & & & & & & 1 & & & & 1 & & \\
\hline SM (Severe mixed pattern) & & 3 & & & & & & & & 1 & & 1 & & & & & & & & & & & & & & & & 1 & & \\
\hline TOTAL & 171 & 96 & 75 & 44 & 33 & 20 & 18 & 5 & 0 & 3 & 3 & 3 & 39 & 4 & 0 & 5 & 0 & 3 & 0 & 1 & 3 & 0 & 0 & 3 & 0 & 1 & 0 & 4 & 0 & 0 \\
\hline
\end{tabular}

Table 6: Agreement between PC and Pneumology Service with respect to spirometric functional diagnosis (2005 vs. 2015).

The lack of quality of the spirometries and the presence of inadequate classification lead to an erroneous clinical diagnosis of the patients with respiratory pathology and thus affects their health and healthcare spending $[6,28,29]$. Undoubtedly, telemedicine programmes have associated investments in health resources that, although in the short term possibly incur increased costs, have proven to be costeffective in view of the results obtained [30].

Our study has limitations, such as the fact that all the selected CSs are urban, and it is reasonable to think that this bias would lead, in any case, to obtaining a better level of quality than that observed in the overall population. As a consideration, the added advantage of being able to perform both tests the same morning was achieved, which minimizes the expected variability between them. The observers were two expert pulmonologists; however, the analyses were not conducted independently, which could pose another constraint.

Recently, in our country, the Ministry of Health, within the framework of the strategy for COPD, has awarded the recognition of good clinical practice to three projects focusing on the improvement and dissemination of spirometry in PC. One of them, the Galician Health Service, promotes short and long-term tutored training of the professionals involved; the other two, the Vasco and La Rioja Health Services, use telemedicine tools for this purpose [31].

\section{Conclusions}

Spirometry in PC continues to be an unresolved problem in our area; furthermore, as we have observed, exclusively training and noncontinuing programmes offer insufficient results. Given the magnitude of the problem and knowledge of the existence of projects that have demonstrated their effectiveness, we believe there should be no further delay in implementing any of these strategies adapted to each area. This same consideration can be extended to other communities with a similar situation.

\section{Acknowledgements}

The authors thank the Primary Care Directorate of the Navarre Health Service (Osasunbidea) for the support and facilities given, all nurses and physicians of the CSs participating in the study (Ansoain CS, Azpilagaña CS, Berriozar CS, Casco Viejo CS, Chantrea CS, Ermitagaña CS, Mendillorri CS, Milagrosa CS, San Jorge CS, San Juan CS) for their efforts, and the nurses of the respiratory function laboratory of the Pneumology Service (María Jesús Martínez and Amparo Urrizburu) for their good work and their availability at all times.

\section{Specific Contribution of Each of the Authors}

Dr. Pilar Cebollero and Javier Hueto participated in the study design, supervision of data collection, analysis of results, and drafting of the manuscript;
Dr. María Carmen Bermejo, Jorge Zagaceta, Francisco Campano, and Izaskun Jiménez participated in the data collection and revision of the manuscript; Dr. José Antonio Cascante participated in the analysis of results and drafting of the manuscript.

\section{References}

1. Raherison C, Girodet PO (2009) Epidemiology of COPD. Eur Respir Rev 18 213-221.

2. Akinbami LJ, Moorman JE, Bailey C, Zahran HS, King M, et al. (2012) Trends in asthma prevalence, health care use, and mortality in the United States, 20012010. NCHS Data Brief 94

3. (2009) COPD Strategy of the National Health System. Ministry of Health and Social Policy, Madrid, Spain.

4. Levy ML, Quanjer PH, Booker R, Cooper BG, Holmes S, et al. (2009) Diagnostic Spirometry in Primary Care. Proposed standards for general practice compliant with American Thoracic Society and European Respiratory Society recommendations. Prim Care Respir J 18: 130-147.

5. Casas A, de Oca MM, López MV, Aguirre C, Schiavi E, et al. (2016) COPD Underdiagnosis and Misdiagnosis in a High-Risk Primary Care Population in Four Latin American Countries. A Key to Enhace Disease Diagnosis: The PUMA Study. PLoS ONE 11: e0152266.

6. Fernández-Villar A, López-Campos JL, Represas C, Marin L, Leiro V, et al. (2015) Factors associated with inadequate diagnosis of COPD: On-Sint cohort analysis. Int J Chron Obstruct Pulmon Dis 10: 961-967.

7. Hill K, Goldstein RS, Guyatt GH, Blouin M, Tan WC, et al. (2010) Prevalence and underdiagnosis of chronic obstructive pulmonary disease among patients at risk in primary care. Can Med Assoc J 182: 673-678.

8. Miravitlles M, Soriano JB, García-Río F, Muñoz L, Duran-Tauleria E, et al (2009) Prevalence of COPD in Spain: impact of undiagnosed COPD on quality of life and daily life activities. Thorax 64: 863-868.

9. Walters JA, Walters EH, Nelson M, Robinson A, Scott J, et al. (2011) Factors associated with misdiagnosis of COPD in primary care. Prim Care Respir $J$ 20: 396-402.

10. Hueto J, Cebollero P, Pascal I, Cascante JA, Eguía VM, et al. (2006) Spirometry in primary care in Navarre, Spain. Arch Bronconeumol 42: 326-331.

11. Marquez-Martín E, Soriano J, Calle M, López-Campo JL (2015) Differences in the use of spirometry between rural and urban primary care centers in Spain. Int J Chron Obstruct Pulmon Dis 10: 1633-1639.

12. Vanjare N, Chhowala S, Madas S, Kodgule R, Gogtay J, et al. (2016) Use of spirometry among chest physicians and primary care physicians in India. NPJ Prim Care Respir Med 26: 16036

13. López-Campos JL, Soriano JB, Calle M (2013) A comprehensive, nationa survey of spirometry in Spain: current bottlenecks and future directions in primary and secondary care. Chest 144: 601-609.

14. Llauger MA, Rosas A, Burgos F, Torrente E, Tresserras R, et al. (2014) Accesibility and use of spirometry in primary care centers in Catalonia. Aten Primaria 46: 298-306. 
Citation: Cebollero PC, Bermejo MC, Cascante JA, Campano F, Zagaceta J, et al. (2016) Are Training Programs Efficient Enough to Improve Spirometry Quality in Primary Care? J Pulm Respir Med 6: 368. doi:10.4172/2161-105X.1000368

15. Masa JF, González MT, Pereira R, Mota M, Riesco JA, et al. (2011) Validity of spirometry performed online. Eur Respir J 37: 911-918.

16. Burgos F, Disdier C, de Santamaria EL, Galdiz B, Roger N, et al. (2012) Telemedicine enhances quality of forced spirometry in primary care. Eur Respir J 39: 1313-1318.

17. Represas-Represas C, Botana-Rial M, Liro-Fenández V, González-Silva Al, García-Martínez A, et al. (2013) Short- and Long-term Effectiveness of a Supervised Training Program in Spirometry Use for Primary Care Professionals. Arch Bronconeumol 49: 378-382.

18. Marina N, de Santamaria EL, Gutierrez A, Bayón JC, García L, et al. (2014) Telemedicine Spirometry Training and Quality Assurance Program in Primary Care Centers of a Public Health System. Telemed J E Health 20: 388-392.

19. Gupta S, Moosa D, MacPherson A, Allen C, Tamari IE (2016) Effects of a 12-month multi-faceted mentoring intervention on knowledge quality, and usage of spirometry in primary care: a before-and-after study. BMC Pulm Med 16: 56.

20. Giraud V, Beauchet A, Gomis T, Chinet T (2016) Feasibility of spirometry in primary care to screen for COPD: a pilot study. Int J Chron Obstruct Pulmon Dis 11: $335-340$.

21. Miller MR, Hankinson J, Brusasco V, Burgos F, Casaburi R, et al. (2005) Standardisation of spirometry. Eur Respir J 26: 319-338.

22. García-Río F, Calle M, Burgos F, Casan P, Del Campo F, et al. (2013) Spirometry. Spanish Society of Pulmonology and Thoracic Surgery (SEPAR). Arch Bronconeumol 49: 388-401.

23. Epton MJ, Stanton JD, McGeoch GR, Shand BI, Swanney MP (2015) The development of a community-based spirometry service in the Canterbury región of New Zealand: observations of new service delivery. NPJ Prim Care Respir Med 25: 15003.

24. Eaton T, Withy S, Garrett JE, Mercer J, Whitlock RM, et al. (1999) Spirometry in primary care practice: the importance of quality assurance and the impact of spirometry workshops. Chest 116: 416-423.

25. Nowinsi A, Romanski E, Przemyslw B, Bednarek M, Puścińska E, et al. (2015) Pilot program on distance training in spirometry testing the technology feasibility study. Pneumonol Alergol Pol 83: 431-435.

26. Thijssing L, van der Heijden J, Melissant C, Chavannes N, Witkamp L, et al (2014) Telepulmonology and telespirometry. In: Lovis C, Séroussi B, Hasman A, Haugaard LP, Saka O, et al., editors. Studies in Health Technology and Informatics. Vol. 205, Amsterdam, IOS Press, The Netherlands. pp. 211-215.

27. Burgos F, Melia U, Vallverdú M, Velickovski F, Lluch-Ariet M, et al. (2014) Clinical Decisión Support Sistem to Enhance Quality Control of Spirometry Using Information and Communication Technologies. JMIR Med Inform 2: e29.

28. Spyratos F, Chloros D, Michalopoulou D, Sichletidis L (2016) Estimating the extend and economic impact of under and overdiagnosis of chronic obstructive pulmonary disease in primary care. Chron Respir Dis 13: 240-246.

29. Yu CW, Fu NS, Tai LE, Kwong CK, Chang Y, et al. (2013) Spirometry is underused in the diagnosis and monitoring of patients with chronic obstructive pulmonary disease (COPD). Int J Chron Obstruct Pulmon Dis 8: 389-395.

30. http://arnas-respiratorio.net/file/profesionales/temasactualidad/estudio_ cruces.pdf

31. http://www.msssi.gob.es/organizacion/sns/planCalidadSNS/BBPP EPOC_2015.htm 